DOI: 10.15690/pf.v12i3.1362

\title{
Л.С. Акимова
}

Северо-Восточный федеральный университет им. М.К. Аммосова, Якутск, Республика Саха (Якутия),

Российская Федерация

\section{Частота применения антибактериальной терапии при острых назофарингитах (J00) среди детей дошкольного возраста в амбулаторных условиях г. Якутска}

\section{Контактная информация:}

Акимова Лора Семёновна, младший научный сотрудник Научно-исследовательского института здоровья Северо-Восточного федерального университета им. М.К. Аммосова

Адpec: 677000, Якутск, Сергеляхское шоссе, д. 4, кор. С-2, тел.: +7 (924) 861-90-70, e-mail: akimovals@mail.ru Статья поступила: 07.12.2014 г., принята к печати: 05.05.2015 г.

Актуальность. Острые респираторные инфекции (ОРИ) занимают ведущее место в структуре общей заболеваемости. В России ежегодно регистрируется около 70 тыс. случаев ОРИ на 100 тыс. детского населения. Максимальная частота острых респираторных инфекций отмечается в возрасте от 6 мес до 6 лет, среди этой группы наиболее высокий уровень заболеваемости отмечается у детей дошкольного возраста. Среди причин острых респираторных заболеваний лидируют вирусные инфекции (до 90\%), и только незначительную часть составляют бактериальные патогены. Несмотря на это, практически в 25-85\% случаев при острых респираторных инфекциях врачи-педиатры назначают своим пациентам антибиотики. Цель. Анализ спектра применяемых антибактериальных препаратов при острых назофарингитах у детей дошкольного возраста в амбулаторных условиях. Методы. В исследовании была сформирована репрезентативная выборка, включающая 1248 амбулаторных карт детей дошкольного возраста. В статье представлены нозологические формы острых респираторных инфекций для изучения спектра назначенных к применению системных антибактериальных препаратов при острых назофарингитах у детей дошкольного возраста в амбулаторных условиях. Результаты. В структуре ОРИ за период 2009-2010 гг. доминирует заболеваемость острыми назофарингитами (более 60\%). В ходе фармакоэпидемиологического анализа выявлена частота применения системных антибиотиков у детей с острыми назофарингитами в амбулаторных условиях. Оказалось, что в 43 (в 2009 г.) и $37 \%$ (в 2010 г.) случаев ОРИ была применена антибактериальная терапия. Чаще всего назначались аминопенициллины, комбинированные пенициллины, макролиды, цефалоспорины 3-го поколения. Заключение. Учитывая преобладание случаев острых назофарингитов среди нозологических форм ОРИ, следует подчеркнуть, что большая часть их имеет неосложненное течение, которое может послужить не менее важным основанием для рационального использования системных антибиотиков по эмпирическому выбору в амбулаторных условиях.

Ключевые слова: острые респираторные инфекции, лечение, дети, острый назофарингит, нозология, антибактериальная терапия, амбулаторные условия.

(Для цитирования: Акимова Л.С. Частота применения антибактериальной терапии при острых назофарингитах (J00) среди детей дошкольного возраста в амбулаторных условиях г. Якутска. Педиатрическая фармакология. $2015 ; 12$ (3): 335-339. doi: 10.15690/pf.v12i3.1362)

\section{ВВЕДЕНИЕ}

Острые респираторные инфекции (ОРИ) занимают одну из основных позиций в структуре общей заболеваемости населения России и наиболее часто отмечаются у детей, превышая показатели заболеваемости взрослых более чем в 2,5-4 раза. Острая респираторная инфекция у детей преобладает не только среди инфекционных заболеваний (почти 90\%), но и в структуре всей впервые зарегистрированной патологии (более 60\%). Несмотря на многообразие возбудителей, считают, что до 95\% заболеваний верхних дыхательных путей в дошкольном возрасте вызвано вирусами: соответственно, их значение в формировании данной патологии является определяющим [1, 2]. Врачу первичного звена очень важно не переоценивать возможную роль бактериальной флоры и воздерживаться от назначения антибактериальных препаратов в тех случаях, когда в этом нет необходимости. Ведь рациональная антибиотикотерапия в педиатрии до сегодняшнего дня остается актуальной и непростой задачей. Несмотря на значительный прогресс в развитии клинической фармакологии, вопросы обоснованности назначения лекарственных средств при ОРИ продолжают сохранять прежние позиции. Это связано с отсутствием согласованных протоколов лечения, преувеличением роли медикаментозной терапии при ОРИ, а также изменением чувствительности возбудителей к антибактериальным препаратам [3, 4]. В структуре инфекционных болезней у детей удельный вес ОРИ достигает 90\%. По данным многочисленных авторов, максимальная заболеваемость ОРИ среди детей отмечается в возрасте от 6 мес до 6 лет и составляет от 4 до 8 заболеваний в год. Среди школьников заболеваемость снижается до 2-5 случаев в год, а среди взрослых - не превышает 2-4 в течение такого же периода времени [5-7].

По статистическим данным Республики Саха (Якутия), с 2000 по 2009 г. ситуация по ОРИ среди детского населения в возрасте 0-14 лет остается на стабильно высоком уровне: в среднем 748,15 зарегистрированных 
Рис. 1. Структура острых респираторных инфекций у детей по нозологиям в 2009 г.

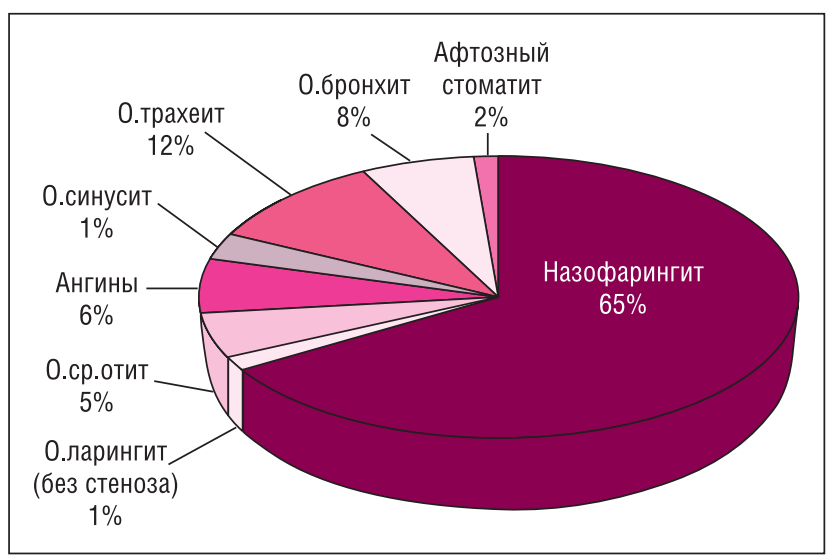

случаев на 1000 детей. В 2003, 2009 и 2010 гг. отмечался заметный рост заболеваемости ОРИ по республике, который составил до 825,1; 955,3 и 891,4 случаев, соответственно [8, 9]. По данным Всемирной организации здравоохранения, ежегодно дети в среднем переносят от 5 до 8 эпизодов ОРИ, нетяжелых по большей части. Но, к сожалению, именно ОРИ вирусного генеза - самый 336 частый повод для нерациональных терапевтических подходов, полипрагмазии, нередко приводящий к серьезным ятрогенным осложнениям.

Известно, что антибиотики не влияют на симптомы ОРИ и не предотвращают бактериальную суперинфекцию, а, скорее, способствуют ее развитию в связи с подавлением нормальной флоры дыхательных путей. Необоснованная частота назначения антибиотиков детям с ОРИ в России остается высокой - от 25 до 85\% $[7,10,11]$.

Эмпирический выбор препарата при острых респираторных инфекциях должен базироваться на рекоменда- циях по стартовой терапии с учетом вероятного возбудителя и его чувствительности в данном регионе. С целью рационализации терапии ОРИ у детей в 2002 г. Союзом педиатров России была создана научно-практическая программа "Острые респираторные заболевания у детей: лечение и профилактика", в которой были освещены основные проявления острых и рецидивирующих респираторных инфекций, а также подходы к их терапии $[3,12]$.

\section{ПАЦИЕНТЫ И МЕТОДЫ}

Дизайн исследования

Для исследования была сформирована репрезентативная группа методом случайной выборки. В выборку были включены амбулаторные карты детей в возрасте от 2 до 6 лет, обратившихся в поликлиническую сеть г. Якутска за период 2009-2010 гг.: оценивались нозологическая структура ОРИ и частота применения антибактериальной терапии. Также был проведен общий фармакоэпидемиологический анализ применения антибиотиков при ОРИ, на основе которого отдельно изучена частота применения системных антибактериальных препаратов при острых назофарингитах у детей.

\section{Статистический анализ}

Статистическая обработка данных проводилась с помощью программы Excel.

\section{РЕЗУЛЬТАТЫ}

Для решения поставленной цели проведен ретроспективный анализ амбулаторных карт 1248 детей в возрасте от 2 до 6 лет, наблюдавшихся на разных участках амбулаторной сети г. Якутска с симптомами острых респираторных заболеваний верхних дыхательных путей: острым назофарингитом, острым ларингитом, острым трахеитом, острым простым бронхитом, ангиной, острым средним отитом, острым синуситом, афтозным стоматитом. За 2009 г. переболели ОРИ всего 598 детей, в том

\section{L.S. Akimova}

Ammosov North-Eastern Federal University, Yakutsk, Republic of Sakha (Yakutia), Russian Federation

\section{The Frequency of Using Antibiotic Therapy for Acute Nasopharyngitis (J00) Among Preschool Children in Outpatient Conditions in Yakutsk}

Background. Acute respiratory infections (ARI) are leaders in the structure of general diseases of the population. In Russia, each year about 70 thousand ARI cases occur per 100 thousand child population. The maximum frequency of acute respiratory infections is noted at the age from 6 months to 6 years. Among this group, the highest incidence of acute respiratory infections is observed for children of preschool age. Viral infections are leading among the causes of acute respiratory disease (90\%) and only a minor part of them consist of bacterial pathogens. Despite this, almost 25-85\% of pediatricians prescribe to their patients antibiotics for acute respiratory infections. The Aim. Analysis of the spectrum of antibacterial drugs used in acute nasopharyngitis in preschool children in an outpatient setting. Methods. The study was formed by a representative group in the amount of 1248 outpatients preschool children. The article presents the nosological forms of acute respiratory infections to study the spectrum of applied systemic antibiotics in acute nasopharyngitis in preschool children in an outpatient setting. Results. In the structure of ARI for the period 2009-2010, the incidence of acute nasopharyngitis dominates and is more than 60\%. During pharmacoepidemiological analysis the frequency of using systemic antibiotics in children with acute nasopharyngitis on an outpatient basis was established. It was found that antibiotic therapy was applied in 43 (2009) and 37\% (2010) ARI cases. Most often it were aminopenicillins, combined penicillins, macrolides, cephalosporins of the III-rd generation. Conclusion. Given the prevalence of acute nasopharyngitis among ARI nosological forms, it should be emphasized that most of them are uncomplicated, which may serve as important basis for the rational use of systemic antibiotics on empirical choice in the conditions of outpatient care. Key words: acute respiratory infections, treatment, children, acute nasopharyngitis, nosology, antibiotic therapy outpatient conditions.

(For citation: Akimova L.S. The Frequency of Using Antibiotic Therapy for Acute Nasopharyngitis (J00) Among Preschool Children in Outpatient Conditions in Yakutsk. Pediatricheskaya farmakologiya - Pediatric pharmacology. 2015; 12 (3): 335-339. doi: 10.15690/pf.v12i3.1362) 
числе 286 (47,8\%) мальчиков и 312 (52,2\%) девочек. За 2010 г. прошли лечение и наблюдение 650 детей с ОРИ, среди которых 327 (50,3\%) мальчиков и 323 (49,7\%) девочки.

Как показал анализ данных за 2009-2010 гг. (рис. 1, 2), в структуре ОРИ первое ранговое место занимал острый назофарингит (974 случая; $64,55 \%$ и 1165; 68,98\%), второе - острый трахеит $(187 ; 12,39 \%$ и 174; $10,30 \%) ;$ третье - острый простой бронхит $(125 ; 8,28 \%$ и 118; 6,99\%); четвертое - ангины (91; 6,03\% и 78; 4,62\%, соответственно).

Рассматривая сезонность ОРИ, можно отметить, что пик заболеваемости приходился на март и апрель как в 2009, так и в 2010 г., а умеренный подъем отмечался в октябре и ноябре с одинаковой частотой обращений.

Как видно из диаграмм (см. рис. 1, 2), в структуре ОРИ пребладают неосложненные формы, такие как острые назофарингиты, трахеиты. Соответственно, большинство ОРИ имеют нетяжелое течение, что подтверждается многими отечественными и зарубежными авторами.

Антибактериальная терапия при ОРИ была применена в 43 (2009) и 37\% (2010) случаев (рис. 3). Процентное соотношение применения антибактериальной терапии за 2009-2010 гг. по отдельным нозологиям представлено на рис. 4. Установлено, что при неосложненных формах ОРИ доля применения антибактериальных препаратов среди всех переболевших детей такова: при остром назофарингите - 17 и 16\%, остром трахеите - 10 и 8\%, соответственно, от общего числа ОРИ (см. рис. 4).

Выявлено, что в 2009 г. при остром назофарингите В 117 (18\%) случаях были назначены к применению аминопенициллины (амоксициллин, ампициллин), в 69 (11\%) - комбинированные пенициллины (резистентные к $\beta$-лактамазе), в 45 (7\%) - макролиды (азитромицин, макропен), и даже в 19 (3\%) случаях применялись цефалоспорины 3-го поколения (Супракс - у 17, Клафоран у 2). В 2010 г. за счет сокращения применения аминопенициллинов увеличилось назначение комбинированных пенициллинов (Амоксиклав и Аугментин, резистентные к $\beta$-лактамазе) на 19 случаев (на 3\%), цефалоспоринов 3-го поколения (Супракс - у 30) - на 11 (на 2\%), макролидов - на 5 (на 1\%) по сравнению с предыдущим годом (рис. 5-7), хотя процент назначения антибиотиков при острых назофарингитах должен был быть сведен к абсолютному нулю.

\section{ОБСУЖДЕНИЕ}

Достижения в борьбе со многими инфекциями выработали уверенность в почти безграничных возможностях антибиотиков, поэтому нередко последние применяются даже при малейшем проявлении инфекции. Среди родителей и медиков стало привычным назначать антибактериальные препараты при незначительном повышении температуры тела, насморке, невыраженном покраснении слизистых оболочек. При таком подходе имеет место снижение антибиотикочувствительных штаммов бактерий и распространение резистентных форм.

Как известно, системная антибиотикотерапия неэффективна при вирусной этиологии ОРИ, поскольку не предотвращает развитие бактериальных осложнений и практически не влияет на течение неосложненного острого респираторного процесса. Но, несмотря на неоспоримые факты, эти препараты продолжают широко использоваться в педиатрической практике [7, 13-16].
Рис. 2. Структура острых респираторных инфекций у детей по нозологиям в 2010 г.

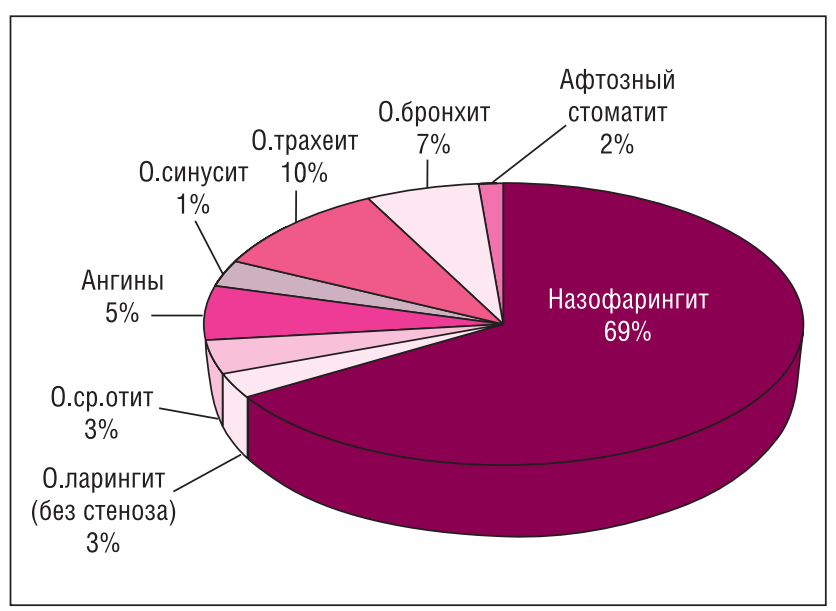

Рис. 3. Частота применения антибиотиков при острых респираторных инфекциях за период 2009-2010 гг.

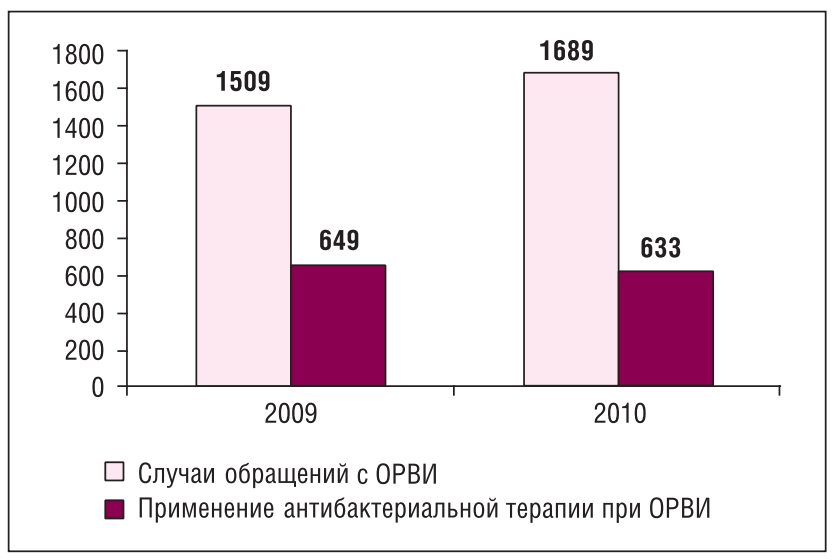

Примечание. ОРВИ - острая респираторная вирусная инфекция.

Рис. 4. Применение антибактериальной терапии по нозологиям за период 2009-2010 гг. (в \%)

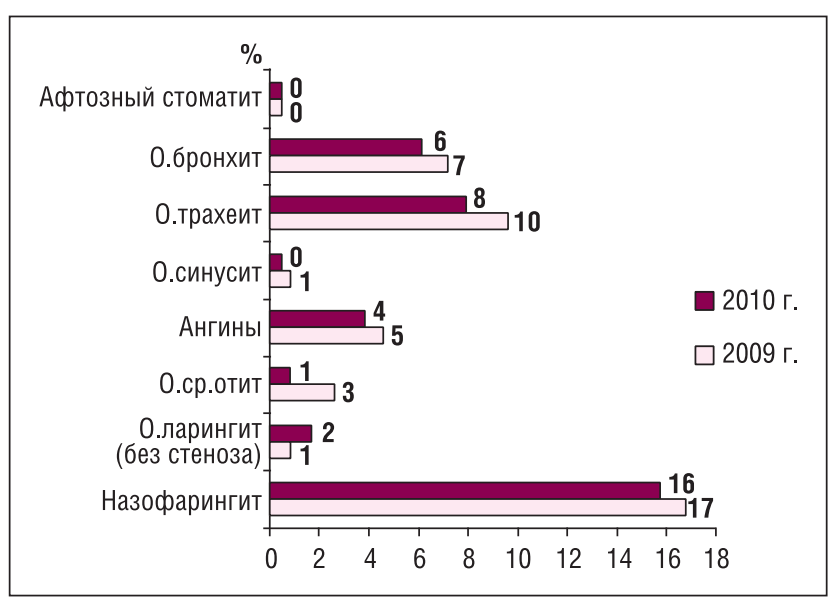

Полученные нами данные указывают на то, что участковые педиатры недостаточно придерживаются выжидательной тактики и динамического наблюдения при таких неосложненных формах, как острые назофарингиты.

Проведенное исследование подтверждает необходимость дальнейшей разработки четких терапевтиче- 
Рис. 5. Частота применения антибактериальных препаратов по нозологиям острых респираторных инфекций за 2009 г. (в \%)

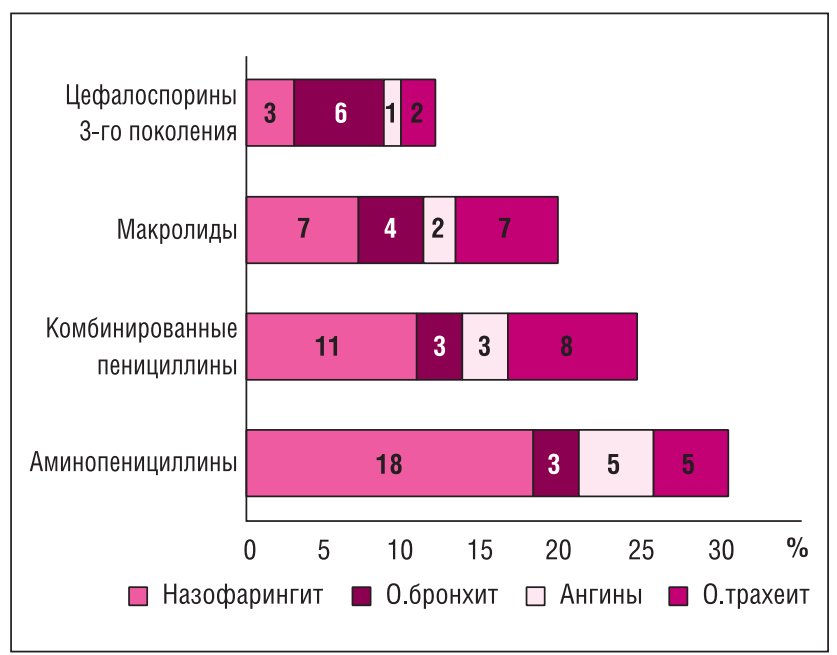

Рис. 6. Частота применения антибактериальных препаратов по нозологиям острых респираторных инфекций за 2010 г. (в \%)

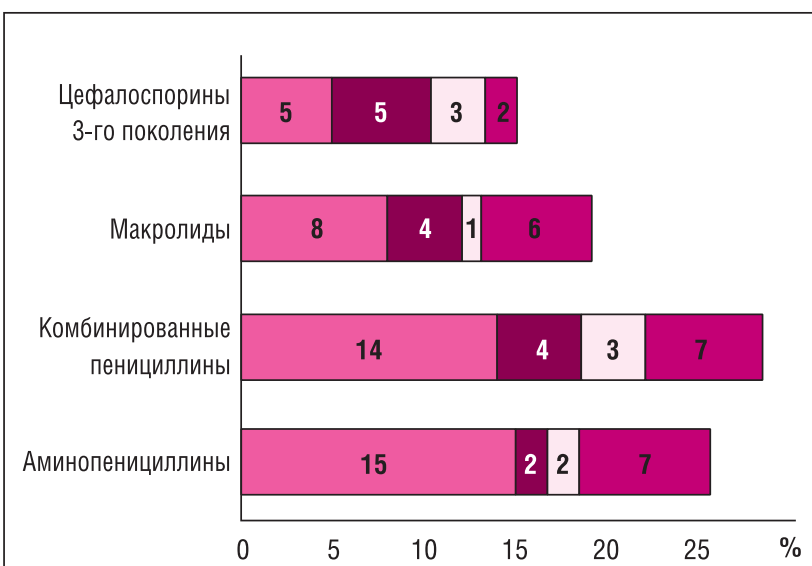

$\square$ Назофарингит $\square$ О.бронхит $\square$ Ангины $\square$ О.трахеит ских рекомендаций и проведения образовательных программ среди участковых педиатров для внедрения современных стандартов диагностики и лечения ОРИ в амбулаторные условия регионов (для совершенствования диагностики действительно тяжелых острых респираторных заболеваний). В целях соблюдения обоснованной антибактериальной терапии острых респираторных инфекций в амбулаторно-поликлинических условиях целесообразно введение строгого учета назначаемых антибиотиков в каждом индивидуальном случае, особенно у часто болеющих и детей раннего возраста. Назначение антибиотика без должных оснований, как указывалось выше, повышает риск побочных явлений и нарушения микробиоты ребенка, способствуя распространению лекарственной устойчивости.

К сожалению, данная статья демонстрирует только часть реальной клинической обстановки амбулаторной помощи. А сколько еще детей продолжает подвергаться агрессивному воздействию такого необоснованного назначения антибактериальных препаратов?

Исходя из полученных данных, зачастую оказывается, что врачу проще назначить антибиотик, чем подвергать риску свою репутацию, даже не попытавшись переубедить родителей в нецелесообразности такого лечения. Хотя, как известно, системная антибиотикотерапия не предотвращает развитие бактериальных осложнений и практически не влияет на течение респираторного процесса. Но, несмотря на убедительные факты, эти препараты продолжают широко использоваться при данной патологии.

Выбор тактики лечения ребенка с ОРИ должен основываться на детальном анализе данных анамнеза с учетом индивидуальных особенностей ребенка, клини ческих проявлений, оценки объективных методов диагностики в динамике, а также результатах лабораторно-инструментальных исследований (по показаниям). у детей при этом должны быть использованы только те лекарственные средства, безопасность и клиническая эффективность которых основаны на принципах доказательной медицины.

Рис. 7. Использование антибактериальных препаратов при острых назофарингитах за период 2009-2010 гг.

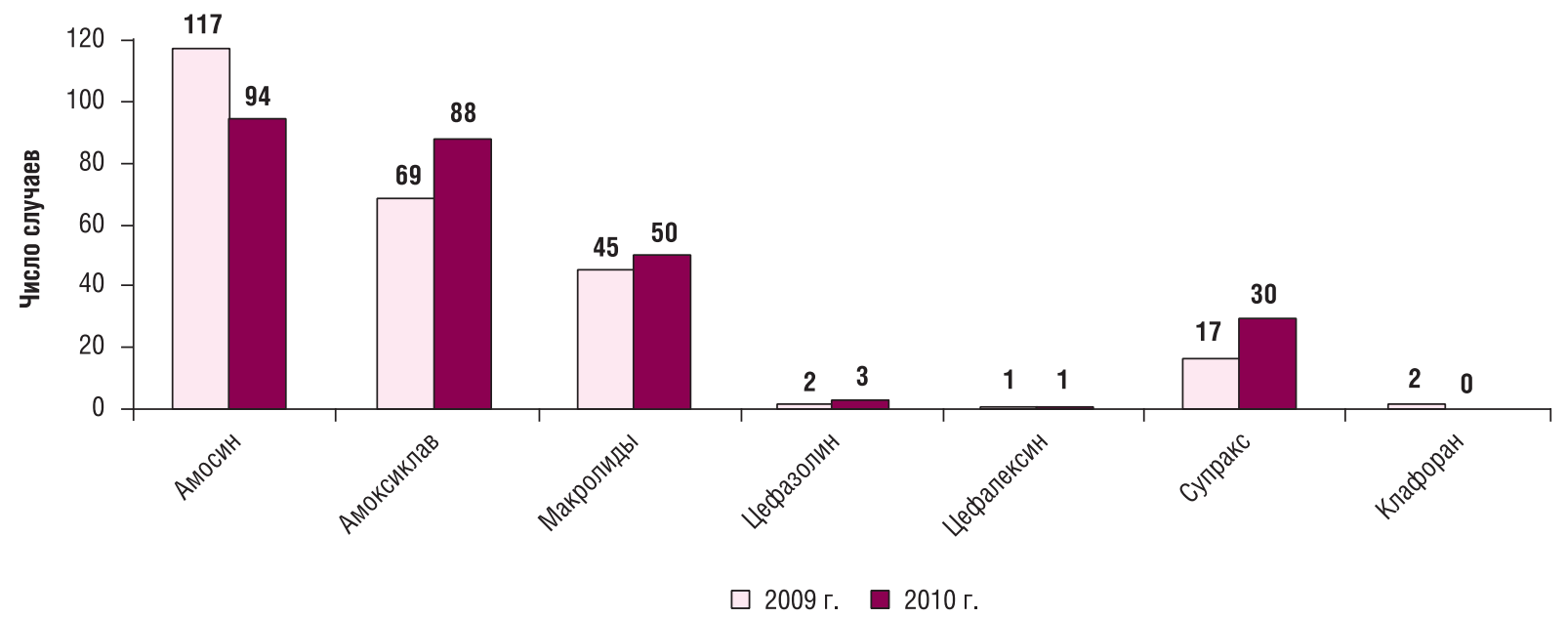


В настоящее время существует острая необходимость повсеместного внедрения новых методов лабораторной экспресс-диагностики с целью дифференцированного подхода к этиологии ОРИ, что позволит ограничить безосновательную антибактериальную терапию, полипрагмазию и выбрать из большого арсенала препаратов оптимальные средства лечения.

\section{выводы}

1. Частота применения антибиотиков при ОРИ за 2009 г. составила 43\%, за 2010 - 37\%.

2. В нозологической структуре ОРИ доминируют случаи острых назофарингитов среди детей дошкольного возраста.

3. Частота применения антибиотиков при острых назофарингитах среди всех ОРИ составила 17 и 16\% за 2009 и 2010 гг., соответственно, что указывает на нерациональное использование антибактериальных препаратов при отсутствии показаний, т.е. при неосложненной форме ОРИ. В частности, среди детей с острыми назофарингитами процент применения антибиотиков составил 26 и 23\% в 2009 и 2010 гг., соответственно.

4. Для лечения острых назофарингитов преимущественно применялись антибиотики группы аминопенициллинов, комбинированных пенициллинов и макролиды, что указывает на несоблюдение стандартов лечения острых назофарингитов.

\section{КОНФЛИКТ ИНТЕРЕСОВ}

Авторы данной статьи подтвердили отсутствие финансовой поддержки / конфликта интересов, о которых необходимо сообщить.

\section{СПИСОК ЛИТЕРАТУРЫ}

1. Баранов А.А., Богомильский М.Р., Волков И.К., Геппе Н.А., Козлов Р.С., Козлова Л.В., Коровина Н.А., Манеров Ф.К., Мизерницкий Ю.Л., Намазова Л.С., Насонова В.А., Самсыгина Г.А., Страчунский Л.С., Сергеева Т.В., Спичак Т.В., Таточенко В.К., Якушин С.Б. Применение антибиотиков у детей в амбулаторной практике. Практические рекомендации. Смоленск: МАКМАХ. 2007. URL: http://www.antibiotic.ru/cmac/pdf/9_3_200.pdf

2. Землякова Э.И., Шакирова Э.М., Сафина Л.з. Экспертный анализ лечения острых респираторных инфекций участковыми педиатрами. Практическая медицина. 2012; 7 (62): 121-125.

3. Намазова Л.С., Таточенко В.К., Бакрадзе М.Д., Волков К.С., Нисевич Л.Л. Применение современных антибиотиков-макролидов в педиатрической практике. Лечащий врач. 2006; 8: 71-73.

4. Краснов В.В. Острые респираторные инфекции у детей (рациональная терапия): пособие для врачей. Н.-Новгород. 2011. 96 с. 5. Альбицкий В.Ю., Баранов А.А. Часто болеющие дети. Клинические и социальные аспекты. Пути оздоровления. Саратов. 1986. C. 45.

6. Самсыгина Г.А. Часто болеющие дети: проблемы патогенеза, диагностики и терапии. Consilium medicum. Приложение "Педиатрия". 2004; 2: 3-10.

7. Таточенко В.К. Болезни органов дыхания у детей: практическое руководство. Москва. 2012. 479 с.

8. Здравоохранение в Республике Саха (Якутия). Стат. сборник. Якутск. 2009. С. 66.

9. Здравоохранение в Республике Саха (Якутия). Стат. сборник. Якутск. 2013. С. 64.
10. Таточенко В.К., Бакрадзе М.Д. Противомикробные и антигельминтные средства. В кн.: Педиатрическая фармакология: лекарственные средства для детей. Под ред. А.А. Баранова. М.: Педиатръ. 2014. 120 c.

11. Antibiotic Resistance: Doctors Antibiotic Prescribing Practices Still Contributing To Problem. Science Daily. 2007 Jul 27. URL: http://www.sciencedaily.com/releases/2007/07

12. Острые респираторные заболевания у детей: лечение и профилактика. Научно-практическая программа Союза педиатров России. М.: Международный фонд охраны здоровья матери и ребенка. 2002. С. 69.

13. Meneghetti A., Mosenifar Z. Upper respiratory tract infection. 2007. URL: http://www.enedicine.medscape.com/article/302460overview

14. Little P., Moore M., Kelly J. Delayed antibiotic prescribing strategies for respiratory tract infections in primary care: pragmatic, factorial, randomized controlled trial. BMJ. 2014 Mar 6; 348: 1606. 15. Hersh A.L., Shapiro D.J., Pavia A.T., Shah S.S. Antibiotic prescribing in ambulatory pediatrics in the United States. Pediatrics. 2011 Nov 7; 128 (6): 1053-1061.

16. Акимова Л.С., Намазова-Баранова Л.С. Фармакоэпидемиологический анализ применения антибактериальной терапии при острых респираторных инфекциях среди детей дошкольного возраста в амбулаторных условиях г. Якутска. Сборник научных трудов Всероссийской научно-практической конференции с международным участием “Современные вопросы педиатрии". Якутск. 2011. С. 15-19. 